\title{
Cardiovascular responses to sustained isometric hand grip during different phases of menstrual cycle- A cross-sectional study
}

\author{
Nirmala S. Anand ${ }^{1, *}$, Shivaprasad .S. Goudar ${ }^{2}$ \\ ${ }^{1}$ Assistant Professor, ${ }^{2}$ Professor, Dept. of Physiology, Jawaharlal Nehru Medical College, Belgaum, Karnataka, India
}

*Corresponding Author:

Email: drnirm79@gmail.com

Received: $17^{\text {th }}$ April, 2018

Accepted: $23^{\text {rd }}$ April, 2018

\begin{abstract}
Introduction: The endogenous gonadal hormones accompanying the menstrual cycle affect the cardiovascular responses to a bout of static isometric exercise. The uncertainty over the consensus as to which phase of menstrual cycle poses greater cardiovascular stress on the female was a question often unanswered.

Aim: The aim of the present study was to assess the influence different phases of menstrual cycle on cardiovascular responses like heart rate, blood pressure, rate pressure product to static isometric handgrip exercise.

Materials and Methods: Thirty eumenorrhic females were examined after using a hand grip dynamometer during the follicular and luteal phases of menstrual cycle.

Statistical Analysis: Data was analysed statistically using student's paired t-test.

Results: It was observed that the baseline values of heart rate in follicular phase was $(78.8 \pm 7.48)$ while in luteal (84 \pm 8.17$)$, SBP in follicular phase $(113.9 \pm 6.63)$ while luteal phase $(115.8 \pm 5.91)$, DBP was $(72.8 \pm 6.90)$ in the follicular phase and $(76.5 \pm$ 6.82) in the luteal phase. MVC at 30\% was maintained for 1, 2 and 4 mins and it was observed that all the values of HR, SBP and DBP were higher in the luteal phase. The rate of fall to baseline for all the cardiovascular parameters i.e.HR, SBP and DBP were higher in the follicular phase compared to the luteal phase.

Conclusion: The results suggest a greater sympathetic activity during the luteal phase to a bout of static isometric exercise hence it can be inferred that the sex steroids lend themselves to an interaction with the ANS indirectly reflecting in cardiovascular system functioning.
\end{abstract}

Keywords: ANS, Isometric, Gonadal, Oestrogen, Vagal.

\section{Introduction}

Menstrual cycle involves a monthly cyclical change in the uterus along with changes in the ovaries which leads to shedding of the endometrial lining and a similar process leading to formation of follicles and shedding of ova from the ovaries. The above mentioned changes are orchestrated due to fluctuating levels of gonadal hormones i.e. oestrogen and progesterone along with the gonadotropins. ${ }^{1,2}$

Physical exercise is a physical stressor which is associated with interactions between the higher centres and peripheral muscles which includes feedback information from ergo receptors in the muscles and feed forward signals from the brain and higher centres and results in alteration in the regulation of the cardiovascular system in the form of changes in heart rate, cardiac output, blood pressure etc. ${ }^{3-6}$ Static isometric exercise has been employed to study the cardiovascular changes in concert with the autonomic changes and also as a therapeutic modality.

Animal studies have shown that exogenous oestrogen application to the spinal cord attenuates increase in $\mathrm{HR}$ and $\mathrm{BP}$ in response to static muscle contractions while endogenous oestrogen causes the release of vasodilator nitric oxide from the endothelium and attenuates the vasoconstrictor tone. ${ }^{7-10}$ It is well documented that the fluctuating gonadal hormones affect various physiological parameters and the fact is confirmed due to the presence of receptors for these sex steroids both at the level of medulla as well as the cardiovascular system, but the extent to which these hormones contribute and the physiological changes caused by their action has not been noted. ${ }^{11}$ Though the cardiovascular functioning is majorly regulated through the two arms of the ANS gender has been considered to have a significant bearing on the working since epidemiological studies have proved that risk factor for cardiovascular emergencies escalates in post menopausal women and the knowledge of this has translated into the use of oestrogen in hormone replacement therapies. ${ }^{12}$

Multiple controversies surrounding the effect of gonadal hormones on cardiovascular reactivity to sustained isometric exercise mandated the conduct of the study.

Objective: The objective of this study was to assess the influence different phases of menstrual cycle on cardiovascular responses like heart rate, blood pressure, rate pressure product to static isometric handgrip exercise.

\section{Materials and Methods}

Study Design: Cross-sectional

Duration: December 2011 till February 2012 
Source of Data: In the present study the data was collected from the students of first year M.B.B.S for the academic year 2011.

Study Setting: Research Lab of department of Physiology

Sample Size: Thirty eumenorrhic girls aged $17 \quad-20$ years of age studying their first year MBBS course were selected

Sample Size Estimation: Expected Reduction$($ MEAN $)=\mathrm{d}=20$

$\mathrm{SD}=40=\sigma$

$\dot{\alpha}=0.05 \quad$ One sided $\quad \mathrm{Z} \dot{\alpha}=1.65$

$\beta=0.2 \quad$ Power $80 \% \quad Z \beta=0.84$

$\mathrm{n}=[(\mathrm{Z} \dot{\alpha}+\mathrm{Z} \beta) \sigma / \mathrm{d}]^{2}=24.8=25=30$

Based on sample size calculation 30 MBBS phase 1 females aged 17-20 years who are eligible were enrolled at the time of data collection.

Inclusion Criteria: Thirty eumenorrhic girls aged 17 20 years of age studying their MBBS course with regular menstrual cycle duration of 28 days at least 2 months prior to the study, having no medical or gynaecological problems, no well-defined premenstrual tension were enrolled.

Exclusion Criteria: Subjects who had irregular menstrual cycles, dysmenorrhea, menorrhagia, had any endocrine disorder or consuming over the counter drugs like cough suppressants, antidepressant, oral contraceptive pill, hormonal replacement therapy, or any other drug that alter the cardiovascular functions were excluded from the study. Females engaging in active exercise i.e.- 3 times/week are excluded from the study since the work extends to sedentary females.

Voluntary informed written consent was obtained from all participants, and the experiment protocol was approved by Ethics committee of the college. A detailed menstrual history which included the no of days, regularity and total duration of cycle was collected prior to enrollment of every participant.

The entire purpose along with a detailed description of the study protocol was given to all the subjects prior to beginning of the test\& examination carried out at same time of the day.

Considering the first day of bleeding as Day 1, the phases marked out were and confirmed by basal body temperature monitoring:

1. Follicular $\left(10^{\text {th }}\right.$ day $)$

2. Luteal $\left(20^{\text {th }}\right.$ day $)$.
Baseline Measurements: Prior to onset of the experimental protocol, the participants underwent blood pressure measurements following $5 \mathrm{~min}$ of supine rest, in a seated position using a standard mercury sphygmomanometer blood pressure cuff and stethoscope.

Experimental Protocol: Subject was instructed and demonstrated the use of a hand grip dynamometer wherein they were asked to grip using maximum force with their dominant hand for few seconds. A mark was made on the dynamometer at 30 percent of the maximum voluntary contraction. The subject was instructed to maintain sustained grip up to 4 minutes. After the subject had started the contraction, the blood pressure was measured on the non-exercising arm at 1 , 2, 4 minute (or any time just before release of grip if it is less than 4 minute).

Highest DBP during test=value.

\section{Precautions}

1. Subject should grip on the dynamometer with maximal effort for the measurement of MVC.

2. The subject should avoid the body movement during and after the test.

Instrument: Jammar hand grip dynamometer Inc, manufactured by INCO Ambala. Values (0-60 Kgs)

\section{Statistical Analysis}

The data quantified as mean \pm SD and analyzed statistically using Student's paired t-test $p<0.05$ was considered to be statistically significant Statistical software SPSS 18 version was used for the analysis of the data.

\section{Results}

Table 1: Shows the distribution of demographic variables

\begin{tabular}{|l|c|}
\hline Age (yrs.) & $18.3 \pm 0.66(17-20)$ \\
\hline Weight $(\mathrm{kg})$ & $56.7 \pm 7.55(47-65)$ \\
\hline Height $\left(\mathrm{m}^{2}\right)$ & $1.56 \pm 0.04(1.51-1.68)$ \\
\hline
\end{tabular}

Table 1 Table I shows the demographic profile of the participants. It is evident that most of the participants are of the mean age group of 18 years and average weight of $56 \mathrm{kgs}$.

Table 2: Baseline cardiovascular parameters

\begin{tabular}{|l|c|c|c|c|}
\hline Variables & Follicular & Luteal & Paired t & P value \\
\hline Heart rate (bpm) & $78.8 \pm 7.48$ & $84 \pm 8.17$ & 3.228 & $0.003^{*}$ \\
\hline $\begin{array}{l}\text { Systolic blood } \\
\text { pressure (mmHg) }\end{array}$ & $113.9 \pm 6.63$ & $115.8 \pm 5.91$ & 3.023 & $0.005^{*}$ \\
\hline $\begin{array}{l}\text { Diastolic blood } \\
\text { pressure (mmHg) }\end{array}$ & $72.8 \pm 6.90$ & $76.5 \pm 6.82$ & 3.354 & $0.002^{*}$ \\
\hline
\end{tabular}

$*_{\text {-Significant, NS-non significant. }}$ 
Table 1 shows the baseline HR, SBP and DBP during both the phases. It is evident the baseline recordings are all higher in the luteal phase compared to the follicular.

Graph 1: Baseline cardiovascular parameters HR, SBP and DBP

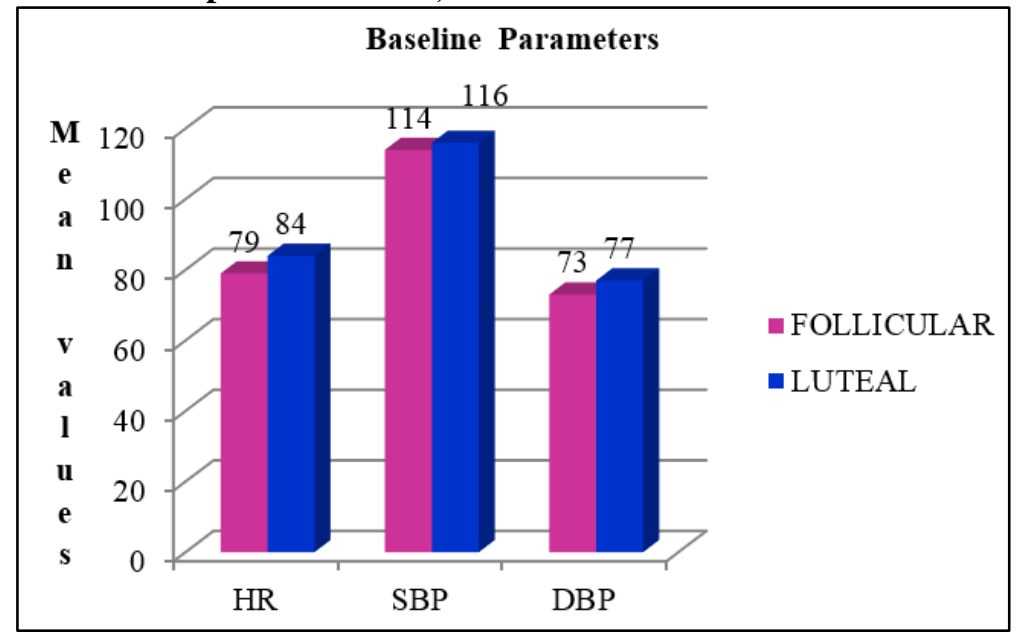

Table 3: Shows the comparison of $\mathrm{HR}$ and blood pressure responses to isometric hand grip exercise at $30 \%$ of MVC at $1 \mathrm{~min}$ between follicular and luteal phases of menstrual cycle

\begin{tabular}{|c|c|c|c|}
\hline 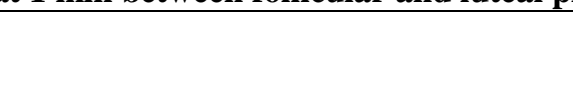 & $\begin{array}{l}\text { Follicular } \\
(\text { mean } \pm \text { SD })\end{array}$ & $\begin{array}{c}\text { Luteal } \\
(\text { mean } \pm \text { SD })\end{array}$ & P value \\
\hline HR (bpm)at $30 \%$ of MVC at $1 \mathrm{~min}$ & $84 \pm 26.45$ & $90.1 \pm 32.34$ & $<0.005^{*}$ \\
\hline $\mathrm{SBP}(\mathrm{mm} \mathrm{HG})$ at $30 \%$ of $\mathrm{MVC}$ at $1 \mathrm{~min}$ & $118.2 \pm 22.51$ & $122.4 \pm 27.35$ & $<0.12^{\mathrm{NS}}$ \\
\hline $\mathrm{DBP}(\mathrm{mm} \mathrm{Hg})$ at $30 \%$ of $\mathrm{MVC}$ at $1 \mathrm{~min}$ & $82.8 \pm 19$ & $90.2 \pm 21.23$ & $<0.005^{*}$ \\
\hline
\end{tabular}

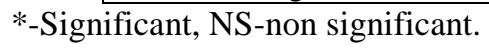

Table 3 shows that the HR as well as DBP to the exercise metaboreflex at 30\% MVC at $1 \mathrm{~min}$ are higher in the luteal phase suggesting a raised SNS activity and a pressor response to a physiological stimuli, while the SBP though higher in the luteal phase seems statistically insignificant.

Table 4: Shows the comparison of $\mathrm{HR}$ and blood pressure responses to $30 \%$ of MVC at 2 min between follicular and luteal phases of menstrual cycle.

\begin{tabular}{|l|c|c|c|}
\hline & $\begin{array}{c}\text { Follicular } \\
(\text { mean } \pm \text { SD })\end{array}$ & $\begin{array}{c}\text { luteal } \\
(\text { mean } \pm \text { SD })\end{array}$ & P value \\
\hline HR $(b p m)$ at 30\% of MVC at 2 min & $85.2 \pm 26.45$ & $91.8 \pm 32.34$ & $<0.005^{*}$ \\
\hline SBP(mm HG)at 30\% min of MVC at 2min & $120 \pm 18.6$ & $126 \pm 20.12$ & $0.01^{\mathrm{NS}}$ \\
\hline DBP(mm Hg)at 30\% of MVC at 2 min & $90.1 \pm 18.3$ & $94.4 \pm 19.11$ & $0.003^{*}$ \\
\hline
\end{tabular}

*-Significant, NS-non significant.

Table 4 shows that the HR as well as DBP to $30 \%$ of MVC are higher in the luteal phase compared to the follicular phase, while the SBP rise seems insignificant between the phases.

Table 5: Shows the comparison of HR and blood pressure responses to $30 \%$ of MVC at 4 min between follicular and luteal phases of menstrual cycle

\begin{tabular}{|l|c|c|c|}
\hline & $\begin{array}{c}\text { Follicular } \\
(\text { mean } \pm \text { SD })\end{array}$ & $\begin{array}{c}\text { Luteal } \\
(\text { mean } \pm \text { SD })\end{array}$ & P value \\
\hline HR $(\mathrm{bpm})$ at 4 min of MVC & $90 \pm 26.45$ & $98.2 \pm 32.34$ & $<0.005^{*}$ \\
\hline SBP(mm HG)at 4 min of MVC & $124 \pm 12.27$ & $130 \pm 14.35$ & $<0.005^{*}$ \\
\hline DBP(mmHg)at 4 min of MVC & $91 \pm 11.5$ & $95.7 \pm 17.76$ & $0.004^{*}$ \\
\hline
\end{tabular}

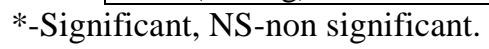

Table 5 shows that the HR, SBP and DBP to $30 \%$ of MVC at 4 min are higher in the luteal phase suggesting a greater sympathetic activity to physical stimuli during the same. 
Table 6: Shows the comparison of HR and blood pressure responses to release of isometric hand grip after 2 min between follicular and luteal phases of menstrual cycle

\begin{tabular}{|c|c|c|c|}
\hline & $\begin{array}{c}\text { Follicular } \\
(\text { mean } \pm \text { SD })\end{array}$ & $\begin{array}{c}\text { Luteal } \\
(\text { mean } \pm \text { SD })\end{array}$ & P value \\
\hline HR (bpm)after 2 min release of MVC & $86 \pm 26.45$ & $89.7 \pm 32.34$ & $<0.005^{*}$ \\
\hline $\mathrm{SBP}(\mathrm{mm} \mathrm{HG})$ after $2 \mathrm{~min}$ of release of $\mathrm{MVC}$ & $119 \pm 30.36$ & $126 \pm 42.48$ & $<0.005^{*}$ \\
\hline $\mathrm{DBP}(\mathrm{mmHg})$ after 2 min of release of MVC & $86 \pm 36.20$ & $92 \pm 41.21$ & $0.001^{*}$ \\
\hline
\end{tabular}

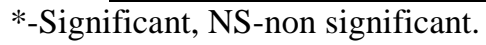

Table 6 shows that the HR, SBP and DBP after 2 mins of release of the hand grip higher in the luteal phase compared to follicular phase, the rate of fall is higher in the follicular phase pointing towards greater vagal activity during follicular phase.

\section{Discussion}

The purpose of the current study was to assess the cardiovascular reactivity in the form of heart rate and blood pressure changes to sustained form of isometric exercise called hand grip dynamometry during different phases of menstrual cycle namely the follicular and luteal phase. The results of the present study suggest a greater heart rate and blood pressure response both at baseline and following the exercise stressor in the form of isometric hand grip dynamometry at $30 \%$ of MVC during the luteal phase of menstrual cycle. The rate of fall of HR, blood pressure both systolic as well as diastolic is higher in the follicular phase. The cardiovascular regulation is extrinsically regulated through the ANS and the gonadal hormones interact with the ANS to produce multitude of effects depending on the cycle phase. ${ }^{13}$ Oestrogen is predominant in follicular phase has been attributed with cardio protective effects and progesterone in the luteal phase has actions which are antagonist to the actions of oestrogen. Hence oestrogen increases the parasympathetic tone and progesterone blocks this action resulting in an increased sympathetic activity during luteal phase. ${ }^{14}$

The current study is unique because it employed an isometric handgrip exercise which is reported to increase both aortic and brachial artery pressures whereas other studies which employed bicycle ergometer exercise only increases brachial artery pressure. ${ }^{15}$ The Heart rate responses to isometric exercise increases initially due to parasympathetic withdrawal and later due to recruitment of central SNS activity. Increase in cardiac output to isometric exercise increases the systolic blood pressure while the vasopressor response from to isometric handgrip exercise in the present study were, therefore, probably mediated by sympathetic release of norepinephrine and activation of alpha-adrenergic receptors causing an increase in diastolic blood pressure. ${ }^{16,17}$ In the current study the heart rate as well as blood pressure responses whether at baseline or following a static exercise stressor seemed to be attenuated in the follicular phase which is a phase of oestrogen dominance. Similar results are corroborated in studies conducted on animals when oestrogen is applied to the spinal cord, oestrogen is known to reduce the production of lactate as well as drive down the sympathetic vasoconstrictor tone and cause vasodilatation. ${ }^{18-21}$ Oestrogen during the follicular phase increases the vagal and decreases sympathetic activity, thus offering cardio protection. ${ }^{22}$ Progesterone during the luteal phase, appears to have an opposing effect, elevating central noradrenaline release. ${ }^{23}$ Similar results have been documented in Postmenopausal women on combined hormone replacement therapy show reduced vagal indices, along with increased heart rate and increased urinary excretion of catecholamines compared to women not taking hormone replacement. ${ }^{24}$ High levels of progesterone in the luteal phase, opposes the positive effects of oestrogen on the autonomic nervous system. ${ }^{24} \mathrm{We}$ hence conclude a significant interaction of the sex steroids with the autonomic transmission which causes variations in cardiovascular functioning during different phases of menstrual cycle.

\section{Conclusion}

The results of our study suggest a greater HR, Blood pressure rise to a bout of static isometric exercise as well as decline of the same towards the baseline is prolonged during the luteal phase as a result of progesterone causing a sympathetic arousal and a marked pressor response to a static isometric exercise suggesting a definite interaction of the HPA axis and the endogenous gonadal hormones.

Implications: Isometric exercises have been prescribed in various settings as a form of therapeutic modality but the cycle based prescription of this form of exercise should be practiced with caution knowing very well that isometric exercises invoke a greater sympathetic response and impose a greater cardiac load during the said phase.

Limitations \& Future Scope: The actual hormone estimation was not conducted due to financial as well as technical constraints. The study can be extended to study the influence of isometric exercise during the bleeding phase as well as to include trained athletes to study the difference in the pattern of influence of different phases of menstrual cycle. 
Acknowledgement: The author would like to thank Mr. Mallapur, statistician who helped analyze the data, the participants for their co-operation and the technical staff for their support.

\section{References}

1. Barrett K.E, Brooks H, Boitano S, Barman S.M. Reproductive Development and Function of the Female Reproductive System. In: 24th edition, Ganong's Review of Medical Physiology. New Delhi: McGraw Hill 2012:391-418

2. Guyton and Hall. Female Physiology before Pregnancy and Female Hormones. In: 12th edition, Textbook of Medical Physiology. Philadelphia: Elsevier 2011:9871002.

3. Alam M \& Smirk FH (1937). Observations in man upon a blood pressure raising reflex arising from the voluntary muscles. J Physiol. 89(4)372-383.

4. Coote JH \& Dodds WN (1976). The baroreceptor reflex and the cardiovascular changes associated with sustained muscular contraction in the cat. Pflugers Arch. 363(2):167-73.

5. Goodwin GM, McCloskey DI \& Mitchell JH (1972). Cardiovascular and respiratory responses to changes in central command during isometric exercise at constant muscle tension. J Physiol. 226(1):173-190.

6. Krogh A \& Lindhard J (1917). A comparison between voluntary and electrically induced muscular work in man. J Physiol. 51(3): 182-201.

7. Schmitt PM \& Kaufman MP (2003b). Estrogen attenuates the exercise pressor reflex in female cats. J Appl Physiol. 95(4):1418-24.

8. Parker BA, Smithmyer SL, Jarvis SS, Ridout SJ, Pawelczyk JA \& Proctor DN (2007). Evidence for reduced sympatholysis in leg resistance vasculature of healthy older women. Am J Physiol Heart Circ Physiol. 292(2):H1148-56.

9. Hashimoto M, Akishita M, Eto M, Ishikawa M, Kozaki K, Toba K, Sagara Y, Taketani Y, Orimo H \& Ouchi Y (1995). Modulation of endothelium-dependent flowmediated dilatation of the brachial artery by sex and menstrual cycle. Circulation. 1995 Dec 15;92(12):34315.

10. Limberg JK, Eldridge MW, Proctor LT, Sebranek JJ \& Schrage WG (2010). $\alpha$-Adrenergic control of blood flow during exercise: effect of sex and menstrual phase. $J$ Appl Physiol. 2010 Nov;109(5):1360-1368. doi: 10.1152/japplphysiol.00518.2010.

11. Sato N, Miyake S, Akatsu J, Kumashiro M. Power spectral analysis of heart rate variability in healthy young women during the normal menstrual cycle. Psychosom Med. 1995;57(4):331-351.

12. Liu CC, Kuo TB, Yang CC. Effects of estrogen on gender-related autonomic differences in humans. Am J Physiol Heart Circ Physiol. 2003;285(5):2188- 93.
13. Mc Fetridge, Judith A. RN, PhD; Sherwood, Andrew PhD. May 2000. Hemodynamic \& Sympathetic Nervous System Responses to stress during the Menstrual Cycle. AACN Clin Issues.. 11(2):158-167.

14. Leicht AS, Hirning DA, Allen GD. Heart rate variability and endogenous sex hormones during the menstrual cycle in young women. Exp Physiol. 2003;88(3):441-446.

15. Tanaka S, Sugiura T, Yamashita S, Dohi Y, Kimura G, Ohte N. Differential response of central blood pressure to isometric and isotonic exercises. Sci Rep. 2014 Jun 25;4:5439. doi: 10.1038/srep05439.

16. Kluess HA, Wood RH, Welsch MA. Vagal modulation of the heart and central hemodynamics during handgrip exercise. Am J Physiol Heart Circ Physiol. 2000;278:H1648-H1652.

17. Gladwell VF, FletcherJ, Patel N, Elvide LJ, Lloyd D, Chowdhary S, Coote JH. The influence of small fibre muscle mechanoreceptors on the cardiac vagus in humans. J Physio. 2005 Sep 1;567(Pt 2):713-21.

18. Kaufman M.P. Metaboreflex control of the heart. $J$ Physiol. 2010 Apr 1;588(Pt 7):1037-1038.

19. Jurkowski JE, Jones NL, Toews CJ \& Sutton JR (1981). Effects of menstrual cycle on blood lactate, O2 delivery, and performance during exercise. J Appl Physiol Respir Environ Exerc Physiol. 1981 Dec;51(6):1493-9.

20. Parker BA, Smithmyer SL, Jarvis SS, Ridout SJ, Pawelczyk JA \& Proctor DN (2007). Evidence for reduced sympatholysis in leg resistance vasculature of healthy older women. Am J Physiol Heart Circ Physiol. 2007 Feb;292(2):H1148-56.

21. Limberg JK, Eldridge MW, Proctor LT, Sebranek JJ \& Schrage WG (2010). $\alpha$-Adrenergic control of blood flow during exercise: effect of sex and menstrual phase. J Appl Physiol. 2010 Nov;109(5):1360-8. doi: 10.1152/japplphysiol.00518.2010.

22. Saleh TM, Connell BJ. Role of oestrogen in the central regulation of autonomic function. Clin Exp Pharmacol Physiol. 2007;34:827-832.

23. Genazzani AR, Stomati M, Morittu A, Bernardi F, Monteleone P, Casarosa E, Gallo R, Salvestroni C, Luisi $\mathrm{M}$. Progesterone, progestagens and the central nervous system. Hum Reprod. 2000;15(Suppl 1):14-27

24. Christ M, Seyffart K, Tillmann HC, Wehling M. Hormone replacement in postmenopausal women: impact of progestogens on autonomic tone and blood pressure regulation. Menopause. 2002;9:127-136

How to cite this article: Anand NS, Goudar SS Cardiovascular responses to sustained isometric hand grip during different phases of menstrual cycle- A cross-sectional study. Ind J Clin Anat Physiol. 2018;5(3):361-365. 